\title{
Development and Significance of Dicarboximide Resistance in Sclerotinia minor Isolates from Commercial Lettuce Fields in California
}

\author{
J. C. Hubbard and K. V. Subbarao, Department of Plant Pathology, University of California, Davis, c/o U.S. Ag- \\ ricultural Research Station, 1636 E. Alisal St., Salinas 93905, and S. T. Koike, University of California Cooperative \\ Extension, 1432 Abbott St., Salinas 93901
}

\begin{abstract}
Hubbard, J. C., Subbarao, K. V., and Koike, S. T. 1997. Development and significance of dicarboximide resistance in Sclerotinia minor isolates from commercial lettuce fields in California. Plant Dis. 81:148-153.

Three growth stages of each of 20 Sclerotinia minor isolates were tested for resistance to iprodione. Sclerotia and both vegetative and mature mycelium of each isolate were plated on potatodextrose agar (PDA) amended with $0,1,5,10,25$, and $100 \mu \mathrm{g}$ of the fungicide per ml, and radial growth was measured. All wild-type field isolates were initially sensitive and did not grow in the presence of iprodione. However, fungicide resistance arose readily in vitro. All 20 isolates produced measurable growth $(\geq 2 \mathrm{~mm})$ on iprodione at $5 \mu \mathrm{g} / \mathrm{ml}$ after 2 weeks when started from mature mycelium, and 18 of 20 isolates produced measurable growth after 4 weeks when started from vegetative mycelium. In general, fungicide-resistant growth arose more frequently and mean colony diameters were significantly greater $(P \leq 0.05)$ with mature mycelium than with vegetative mycelium at all times and concentrations. In sclerotial germination tests, at least $1 \%$ of sclerotia germinated in 18 of 20 isolates after 2 weeks on iprodione at $5 \mu \mathrm{g} / \mathrm{ml}$, and in 19 of 20 isolates after 5 weeks on $100 \mu \mathrm{g} / \mathrm{ml}$. Of growth produced on 79 plates containing iprodione, 73 remained viable on PDA after 5 months, and 71 retained resistance to $5 \mu \mathrm{g} / \mathrm{ml}$. Seventy of these also exhibited cross-resistance to vinclozolin, another dicarboximide fungicide. Pathogenicity of five fungicide-resistant strains was tested in greenhouse, microplot, and field experiments, with and without iprodione. Two months after in vitro production, one of the five resistant strains was avirulent, but disease incidence for the other four ranged from 40 to $75 \%$, compared with $40 \%$ for the wild-type isolates. However, the virulence of the fungicide-resistant strains declined over time. Ten months after their production, two of the isolates were avirulent and disease incidence for the others ranged from 3 to $17 \%$, compared with 40 to $90 \%$ for the wild-type isolates. The strains that remained virulent 5 and 7 months after in vitro production were not significantly controlled by iprodione sprayed according to labeled rates, although disease was significantly controlled by the fungicide in treatments inoculated with wild-type field isolates $(P>0.05)$. In experiments in commercial fields to determine the efficacy of fungicide sprays on the wild-type $S$. minor population, there was no evidence that fungicide resistance was the cause of lack of lettuce drop control observed in many coastal California fields. Application of fungicides at a less than optimal time may account for some incidents of control failure.
\end{abstract}

Lettuce is an economically important crop grown almost year-round in coastal California. The incidence of lettuce drop, incited in this area by Sclerotinia minor Jagger, is widespread and in some years causes significant yield losses. The pathogen persists in the soil as sclerotia, which can germinate and infect lettuce crown and root tissues, causing plants to wilt and die $(2,10)$. Currently, the fungicides iprodione (Rovral, Rhone-Poulenc Ag Company, Research Triangle Park, NC), vinclozolin (Ronilan, BASF Corp. Research Triangle Park, NC), and dicloran (Botran, Gowan Company, Yuma, AZ) are applied immedi-

Corresponding author: J. C. Hubbard

E-mail: jahubbard@ucdavis.edu

Accepted for publication 9 October 1996.

Publication no. D-1996-1203-07R

(C) 1997 The American Phytopathological Society ately after thinning for disease control (10). In recent years, losses have sometimes been severe despite fungicide use, and the efficacy of the currently used fungicides, spray schedules, and spray techniques have been questioned. Possible explanations for failure of the fungicides to control disease are: (i) that resistant strains of $S$. minor have developed with continued fungicide use; (ii) that fungicide applications are not being timed properly and plants are too large at the time of application for effective coverage of the soil surface; and (iii) that continued use of the fungicides has increased the population of soil microflora that rapidly degrade the chemicals $(11,14,18)$.

Field isolates with resistance to dicarboximide fungicides (i.e., iprodione, vinclozolin, and procymidone) have been reported in $S$. minor from peanut in Virginia (3) and Sclerotinia homoeocarpa F.T. Bennett from creeping bentgrass in Michigan (6), but have not been identified in
California. In addition, most fungi tested produced strains resistant to dicarboximide fungicides under laboratory conditions $(5,7,9,13,17)$. Study of in vitro-derived fungicide-resistant strains of California lettuce isolates of $S$. minor that arose with long-term exposure to the fungicides might provide information useful in understanding the potential for problems of resistance that arise in field situations. The objectives of this study were to: (i) collect S. minor isolates from lettuce fields in coastal California and screen them for resistance to iprodione; (ii) examine in vitro-derived fungicide-resistant strains of $S$. minor from these lettuce isolates for stability of resistance, virulence, and ability to cause disease on iprodione-sprayed lettuce plants; and (iii) test the efficacy of iprodione applied immediately after thinning for lettuce drop control in commercial fields. A preliminary report has been published (8).

\section{MATERIALS AND METHODS}

Isolates. Lettuce heads showing symptoms of drop were collected from several locations, and single sclerotial isolates of $S$. minor were obtained. Seventeen of these lettuce isolates were selected, as well as three single sclerotial isolates from other crops (Table 1).

In vitro evaluation of iprodione resistance. Experiments were conducted with both vegetative (the margins of actively growing cultures) and mature mycelium (beginning to differentiate into sclerotia). A 4-mm-diameter agar disk from a potatodextrose agar (PDA) culture of each isolate was plated on PDA amended with $0,1,5$, 10,25 , or $100 \mu \mathrm{g}$ of iprodione per $\mathrm{ml}$ (Rovral 4F). All concentrations are expressed as active ingredient. All plates were incubated at room temperature $(22 \pm$ $2^{\circ} \mathrm{C}$ ), and colony diameters were measured weekly for 4 to 5 weeks. The experiment was conducted twice.

Seventy-nine cultures that grew on plates containing iprodione at $5 \mu \mathrm{g} / \mathrm{ml}$ or higher were stored on those plates, and about 5 months later, they were transferred to plates containing unamended PDA. Vegetative mycelium from cultures that were still viable was then transferred to PDA amended with $5 \mu \mathrm{g}$ of either iprodione or vinclozolin per $\mathrm{ml}$ to test the stability of resistance to iprodione and the crossresistance to vinclozolin. Colony diameters 
were measured after 14 days of incubation at room temperature.

Germination of sclerotia was determined by plating 25 axenically grown sclerotia of each isolate on two dishes of media amended with iprodione at $0,1,5,10,25$, or $100 \mu \mathrm{g} / \mathrm{ml}$. Sclerotia were not considered to have germinated unless the developing colony grew at least $1 \mathrm{~cm}$ diameter on the medium. Germinated sclerotia were counted weekly for 5 weeks, and the experiment was conducted twice.

Analysis of variance was conducted on colony diameter and germination data to test the effects of experiment, isolate, age of mycelium, concentration of iprodione, and interactions. Means were compared using LSD tests $(P \leq 0.05)$. The concentration of iprodione at which sclerotial germination was inhibited by $50 \%$ was estimated using regression analysis. All analyses were conducted using SAS (SAS Release 6.11 ed., SAS Institute, Cary, NC).

Control by iprodione of disease caused by resistant strains. The ability of iprodione to control lettuce drop incited by in vitro-derived fungicide-resistant strains was tested in microplot and greenhouse experiments. Inoculum was produced by growing $S$. minor for 3 weeks at room temperature on autoclaved rye seed (1). Microplots $1.2 \mathrm{~m}^{2}$ at the U.S. Agricultural Research Station in Salinas were direct seeded with lettuce cv. Salinas in two rows on each of two 1-m-long beds per plot. Plants were thinned to about $25 \mathrm{~cm}$ apart in each row 3 weeks after emergence. Plants and the soil surface of one bed in each microplot were sprayed with iprodione (1,200 ppm) 2 days after thinning; one bed was left unsprayed. One week after spraying, lettuce plants on both beds in each plot were inoculated by placing one infested rye seed, with associated mycelium and sclerotia, $1 \mathrm{~cm}$ from the crown of each plant. One wild-type sensitive isolate and five resistant strains (randomly chosen) were tested. Four replicate microplots were maintained for each strain or isolate, and the assignment of a microplot to a given isolate or strain was completely random. Plots were furrow irrigated, and the incidence of lettuce drop was recorded at weekly intervals for 8 weeks. Mean disease incidence was calculated, and corresponding standard errors were computed.

The same $S$. minor isolates and strains were also evaluated in a greenhouse experiment. Lettuce cv. Salinas was grown in $9 \mathrm{~cm}^{2}$ pots containing one plant per pot. At the three-leaf stage, plants and the soil surface in half the pots were sprayed with 1,200 ppm iprodione. Two days later, 10 pots each, sprayed and unsprayed, were inoculated with each isolate or strain by placing one infested rye seed $1 \mathrm{~cm}$ from the crown of the plant. Care was taken to avoid disturbing the soil surface. Pots were irrigated by adding water to the saucers. Incidence of drop was recorded daily for 10 weeks.

Temporal variations in the virulence of iprodione-resistant strains. The virulence (measured as the level of lettuce drop incidence) of five fungicide-resistant strains was tested in five separate experi- ments conducted between 2 and 10 months after their production. Tests included the above microplot and greenhouse experiments conducted 5 and 7 months after production, and two other greenhouse experiments conducted 2 and 3 months after production. In the latter experiments, the resistant strains were compared with their wild-type counterparts. Plants were inoculated as above using 20 plants per isolate in each test; no fungicide was used. Incidence of drop was recorded daily for 10 weeks.

Pathogenicity of the fungicide-resistant strains was again compared with their wild-type counterparts in a field experiment conducted 10 months after production of the resistant strains. Lettuce (cv. Salinas) was planted in double rows 30.5 $\mathrm{cm}$ apart with plants $25 \mathrm{~cm}$ apart in the rows. Ten plants per isolate or strain were inoculated as above. The experimental design was a randomized block with three replicates. The number of plants showing lettuce drop symptoms was counted in all plots at weekly intervals until harvest. Means and the corresponding standard errors of the mean were computed for each isolate or strain.

Evaluation of field spray schedules. Efficacy of the currently used fungicides and spray schedules was evaluated during 1993 and 1994 in commercial fields with a history of high lettuce drop incidence. In 1993, experiments were conducted in three fields. Fields 1, 2, and 3 were sprinkler, furrow, and subsurface-drip irrigated, respectively. Treatments were: (i) iprodione (Rovral) applied post-thinning at 2.24

Table 1. Sclerotinia minor isolates screened for resistance to iprodione, with their host and location of origin, collector, and reactions in vitro to the fungicide

\begin{tabular}{|c|c|c|c|c|c|c|c|}
\hline \multirow[b]{2}{*}{ Isolate } & \multirow[b]{2}{*}{ Host } & \multirow[b]{2}{*}{ Location } & \multirow[b]{2}{*}{ Year } & \multirow[b]{2}{*}{ Collector } & \multicolumn{2}{|c|}{ Mean colony diameter } & \multirow{2}{*}{$\begin{array}{l}\text { Sclerotia } \\
(\mu \mathrm{g} / \mathrm{ml})^{\mathrm{b}}\end{array}$} \\
\hline & & & & & Vegetative & Mature & \\
\hline $\mathrm{SC} 2$ & Peanut & Oklahoma & $\ldots$ & J. P. Damicone & $23.2 \pm 4.5$ & $40.0 \pm 10.0$ & 7.7 \\
\hline SC6 & Peanut & Oklahoma & $\ldots$ & J. P. Damicone & $47.0 \pm 7.3$ & $51.0 \pm 10.2$ & 1.6 \\
\hline $\mathrm{SM} 1^{\mathrm{c}}$ & Cauliflower & Salinas, CA & 1992 & K. V. Subbarao & $21.2 \pm 9.8$ & $61.7 \pm 11.1$ & 8.9 \\
\hline SM2 & Lettuce & Salinas, CA & 1992 & K. V. Subbarao & 0 & $30.8 \pm 11.5$ & 6.4 \\
\hline SM3 & Lettuce & Salinas, CA & 1992 & K. V. Subbarao & $3.7 \pm 1.9$ & $47.3 \pm 12.2$ & 4.6 \\
\hline SM4 & Lettuce & Salinas, CA & 1992 & K. V. Subbarao & $6.0 \pm 2.7$ & $39.5 \pm 10.2$ & 6.5 \\
\hline SM5 & Lettuce & Salinas, CA & 1992 & K. V. Subbarao & $22.5 \pm 11.8$ & $37.2 \pm 9.8$ & 9.5 \\
\hline SM6 & Lettuce & Salinas, CA & 1993 & J. C. Hubbard & 0 & $45.2 \pm 13.2$ & 5.4 \\
\hline SM7 & Lettuce & Salinas, CA & 1993 & J. C. Hubbard & $10.0 \pm 2.8$ & $38.3 \pm 10.5$ & 9.3 \\
\hline SM8 & Lettuce & Salinas, CA & 1993 & J. C. Hubbard & $5.0 \pm 5.0$ & $31.7 \pm 6.1$ & 3.6 \\
\hline SM9 & Lettuce & Salinas, CA & 1993 & J. C. Hubbard & $3.5 \pm 1.6$ & $19.3 \pm 4.8$ & 5.4 \\
\hline SM10 & Lettuce & Salinas, CA & 1993 & J. C. Hubbard & $27.2 \pm 10.2$ & $44.5 \pm 12.4$ & 9.3 \\
\hline SM11 & Lettuce & Salinas, CA & 1993 & J. C. Hubbard & $21.2 \pm 5.1$ & $35.7 \pm 8.3$ & 6.7 \\
\hline SM12 & Lettuce & Salinas, CA & 1993 & S. T. Koike & $35.8 \pm 6.6$ & $38.0 \pm 5.8$ & 9.4 \\
\hline SM13 & Lettuce & Salinas, CA & 1993 & S. T. Koike & $28.3 \pm 8.1$ & $26.2 \pm 2.5$ & 12.3 \\
\hline SM14 & Lettuce & Salinas, CA & 1993 & S. T. Koike & 0 & $23.7 \pm 12.4$ & $<1$ \\
\hline SM15 & Lettuce & Salinas, CA & 1993 & S. T. Koike & $3.3 \pm 1.6$ & $15.3 \pm 3.1$ & 7.4 \\
\hline SM16 & Lettuce & Salinas, CA & 1993 & S. T. Koike & $4.3 \pm 2.3$ & $21.8 \pm 5.4$ & 6.4 \\
\hline SM17 & Lettuce & Salinas, CA & 1993 & S. T. Koike & $11.0 \pm 4.3$ & $36.0 \pm 10.3$ & 8.2 \\
\hline SM18 & Lettuce & Santa Maria, CA & 1993 & F. F. Laemmlen & $8.3 \pm 3.8$ & $32.0 \pm 11.7$ & 6.2 \\
\hline
\end{tabular}

a Disks $4 \mathrm{~mm}$ in diameter from agar cultures of $S$. minor were placed at the center of 85-mm petri plates containing potato-dextrose agar (PDA) amended with $5 \mu \mathrm{g}$ of iprodione per ml. Both vegetative mycelium (the margins of actively growing cultures) and mature mycelium (beginning to form sclerotia) were plated for each isolate. Mean colony diameters were determined 3 weeks after plating. On unamended PDA, colonies reached the edges of plates in 3 days.

b Micrograms per $\mathrm{ml}$ of iprodione at which of $50 \%$ of $S$. minor sclerotia germinated when plated on PDA containing 0 , $1,5,10,25$, and $100 \mu \mathrm{g}$ of iprodione per ml. Regression analysis was conducted on germination percent versus fungicide concentration at 3 weeks of incubation. Values for $50 \%$ germination of each isolate were extrapolated from the parameters. On unamended PDA, 100\% of sclerotia germinated within 3 days.

c Lettuce and cauliflower are rotated regularly in this field. 
$\mathrm{kg} / \mathrm{ha}$; (ii) vinclozolin (Ronilan) applied post-thinning at $2.24 \mathrm{~kg} / \mathrm{ha}$; (iii) dicloran (Botran) applied post-thinning at 4.48 $\mathrm{kg} / \mathrm{ha}$; (iv) iprodione applied postplanting at $1.12 \mathrm{~kg} / \mathrm{ha}$ and post-thinning at 2.24 $\mathrm{kg} / \mathrm{ha}$; (v) iprodione applied postemergence at $1.68 \mathrm{~kg} / \mathrm{ha}$ and post-thinning at 1.68 $\mathrm{kg} / \mathrm{ha}$; (vi) untreated control; and (vii) in field 3 , an additional treatment involving dicloran at $4.48 \mathrm{~kg} / \mathrm{ha}$ and iprodione at $2.24 \mathrm{~kg} / \mathrm{ha}$ applied post-thinning. Plots were four beds wide in fields 1 and 2, and eight beds wide in field 3 , and were 106.8, 192.2, and $198.3 \mathrm{~m}$ long, respectively. In 1994, the experiments were conducted in two fields (fields 4 and 5), which were
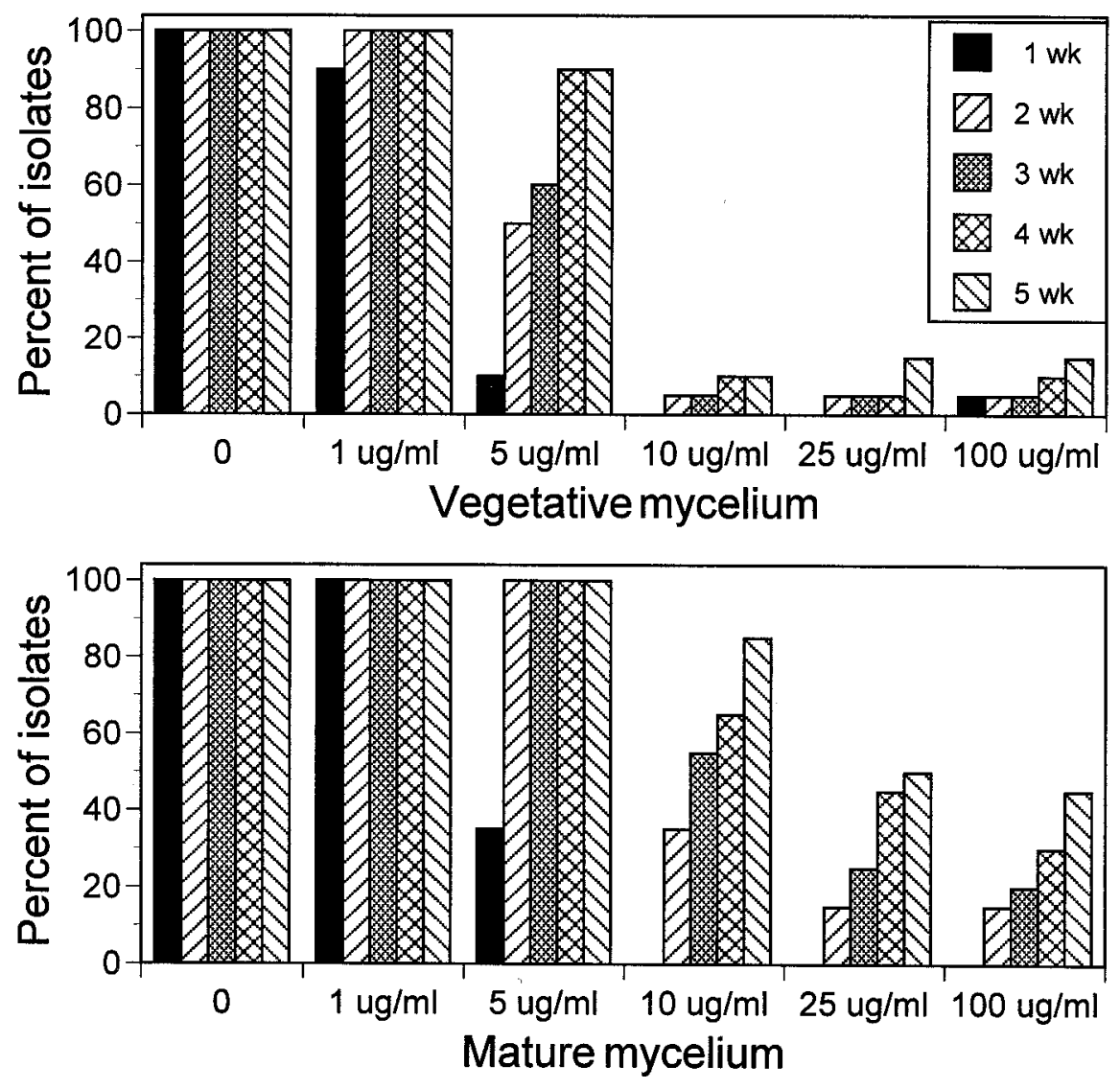

Fig. 1. Percentage of 20 Sclerotinia minor isolates showing at least $2 \mathrm{~mm}$ of growth on potato-dextrose agar (PDA) amended with different concentrations of iprodione. Growth was measured weekly for 5 weeks. Vegetative mycelium was plated from the actively growing margins of PDA cultures; mature mycelium was plated from PDA cultures beginning to form sclerotia.

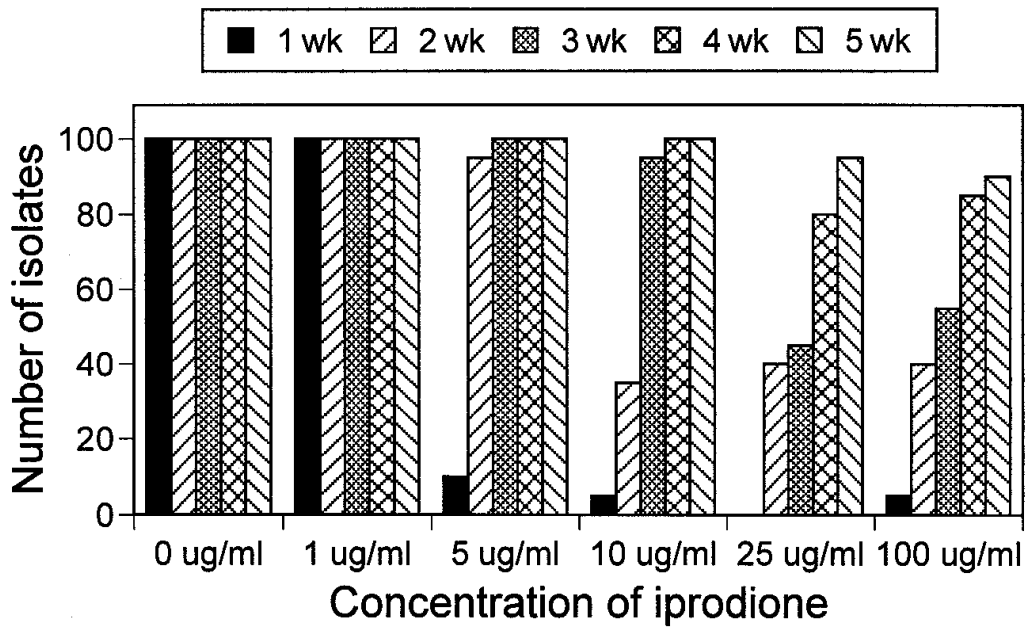

Fig. 2. Percentage of isolates of Sclerotinia minor (out of 20) in which at least one sclerotium out of 100 germinated and produced colonies at least $1 \mathrm{~cm}$ in diameter on potato-dextrose agar amended with different concentrations of iprodione. Germination was recorded weekly for 5 weeks. furrow irrigated. Treatments 1, 2, 3, and 6 included in the 1993 experiment were tested. Plots in field 4 were eight beds wide and $198.2 \mathrm{~m}$ long, and in field 5, they were eight beds wide and $366 \mathrm{~m}$ long. In all five fields, the crops were managed using standard commercial practices by the grower cooperators. The crops were thinned on a timely basis to prevent overly large plant and leaf sizes from interfering with the delivery of fungicides to target areas. Treatments were applied by commercial pesticide applicators using ground rig equipment. All treatments in 1993 and 1994 were arranged in a randomized block design with four replicates of each treatment. Plots were evaluated just before harvest for disease incidence in the following assessment areas: in field 1, 10 randomly chosen four-bed by $6.1-\mathrm{m}$ sections; in field 2, two beds by $192.2 \mathrm{~m}$; in field 3, six beds by $198.3 \mathrm{~m}$; and in fields 4 and 5, eight one-bed by $30.5-\mathrm{m}$ sections. Analysis of variance was conducted to determine the effects of treatments, and treatment means were compared using an LSD test $(P \leq 0.05)$.

\section{RESULTS}

In vitro evaluation of iprodione resistance. All wild-type field isolates of $S$. minor were initially sensitive to iprodione. On unamended PDA, both vegetative and mature mycelium of all isolates covered the $85-\mathrm{mm}$ petri dishes within 3 days. On PDA amended with $1 \mu \mathrm{g} / \mathrm{ml}$, the lowest concentration tested, vegetative mycelium of all isolates showed no growth at 3 days, and mature mycelium had not grown at all or showed a maximum of $2 \mathrm{~mm}$ of growth. However, after a period of incubation on the fungicide-amended media, many cultures began to grow, at varying rates. Although colonies were sometimes irregular in appearance and outline, it generally appeared that the whole colony grew, rather than individual sectors. Within 4 weeks, 18 of 20 isolates showed at least 2 $\mathrm{mm}$ of fungicide-resistant growth at $5 \mu \mathrm{g}$ of iprodione per $\mathrm{ml}$ on plates inoculated with vegetative mycelium. Plates inoculated with mature mycelium from all 20 isolates showed at least $2 \mathrm{~mm}$ of growth within 2 weeks at $5 \mu \mathrm{g} / \mathrm{ml}$. Three isolates grew at least $2 \mathrm{~mm}$ at $100 \mu \mathrm{g} / \mathrm{ml}$ when started from vegetative mycelium, and nine isolates when started from mature mycelium, seven of which grew $72 \mathrm{~mm}$ or more in the 5-week test period. In general, fungicide-resistant growth was observed more frequently with mature mycelium than with vegetative mycelium (Table 1, Fig. 1). In sclerotial germination tests, at least $1 \%$ of the sclerotia germinated within 2 weeks for 18 of 20 isolates at $5 \mu \mathrm{g}$ of iprodione per $\mathrm{ml}$. After 5 weeks, at least $1 \%$ of sclerotia germinated at $100 \mu \mathrm{g} / \mathrm{ml}$ for 19 of 20 isolates (Fig. 2).

Analysis of variance indicated that the results from repeats of the two experiments 
were consistent. The greatest variation in colony diameter was explained by the concentration of iprodione followed by the type of inoculum (vegetative or mature) tested. None of the interactions were significant, indicating that all isolates were consistent in their reaction with respect to the type of inoculum and to iprodione concentration. Iprodione concentration had the greatest effect on sclerotial germination. The interaction between isolate and concentration was significant, indicating that there was a differential response of $S$. $m i$ nor isolates to iprodione concentration (Table 1).

Of the 79 in vitro-derived resistant strains transferred to unamended PDA after approximately 5 months, 73 were viable, and 71 of these retained resistance when transferred back to media containing $5 \mu \mathrm{g}$ of iprodione per ml. Growth rates of the resistant strains were variable, although the rate for each strain was similar on unamended and on fungicide-amended media. Seventy of the 71 strains that retained resistance to iprodione were also resistant to $5 \mu \mathrm{g}$ of vinclozolin per $\mathrm{ml}$.

Control by iprodione of disease caused by resistant strains. The microplot experiment evaluating disease control in fungicide-sprayed and unsprayed treatments was conducted 5 months after in vitro production of the resistant strains. In plots inoculated with the wild-type isolate SM18, there was a significant difference in disease incidence between fungicidesprayed and unsprayed rows (31\% versus $86 \%$ ). Four of the five resistant strains used were only weakly virulent at that time, and differences between sprayed and unsprayed treatments were not significant.

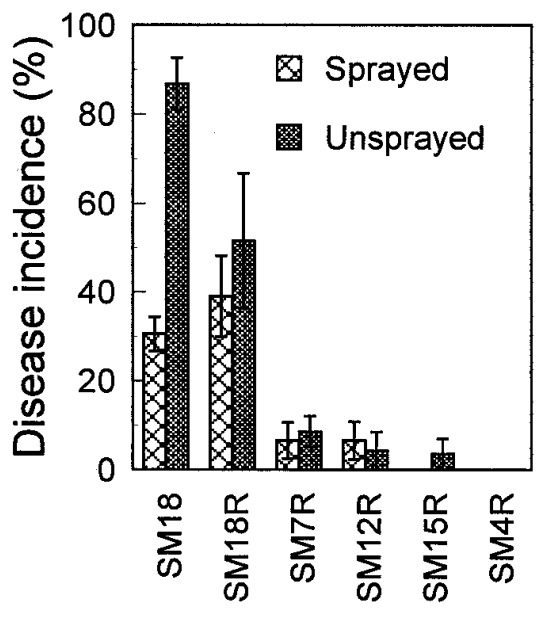
Sclerotinia minor isolate

Fig. 3. Lettuce drop incidence in microplots inoculated with one of five iprodione-resistant strains of Sclerotinia minor (SM4R to SM18R) or one wild-type sensitive counterpart (SM18). Individual rows were either unsprayed or sprayed with iprodione $(1,200 \mathrm{ppm})$ immediately after thinning. Disease incidence was recorded 8 weeks after inoculation.
However, strain SM18R, a fungicide-resistant strain derived in vitro from wildtype isolate SM18, caused $52 \%$ disease incidence in unsprayed plots. While incidence was lower in sprayed plots (39\%), this difference was not significant, indicating that for SM18R (the only virulent resistant strain tested), iprodione did not significantly control disease, whereas disease control was achieved for the wild-type isolate (Fig. 3).

In a greenhouse experiment conducted 7 months after production of the resistant strains, disease incidence for the wild-type isolate SM18 was again higher for unsprayed $(50 \%)$ than for sprayed $(20 \%)$ treatments. Two of the resistant strains caused no disease; but for three strains, disease incidence in fungicide-sprayed treatments was equal to or higher than in unsprayed treatments. The incidence in sprayed and unsprayed treatments, respectively, was 20 and $20 \%$ for SM18R, 10 and $0 \%$ for SM15R, and 20 and $10 \%$ for SM7R, indicating again that in vitro-derived resistant strains were capable of causing disease and of overcoming control by iprodione.

Temporal variation in the virulence of in vitro-derived strains. Results for all five experiments in which the virulence of the fungicide-resistant strains was tested are summarized in Figure 4. In the initial test, conducted 2 months after production of the fungicide-resistant strains, four of the five killed between 40 and $75 \%$ of inoculated lettuce plants, while one strain was avirulent. One month later, virulence had dropped for the remaining four and in general continued to decline over time until at 7 and 10 months, the highest level of disease incidence for the resistant strains was about $20 \%$. In the field test in which the pathogenicity of wild-type field isolates was compared with fungicide-resistant strains derived from those isolates (10 months after the resistant growth arose in vitro), all of the wild-type isolates were more virulent than their corresponding resistant strains: $37 \%$ disease incidence for SM4 versus $0 \%$ for SM4R, 67\% for SM7 versus $17 \%$ for $\mathrm{SM} 7 \mathrm{R}, 77 \%$ for $\mathrm{SM} 12$ versus $7 \%$ for SM12R, 63\% for SM15 versus $0 \%$ for SM15R, and $90 \%$ for SM18 versus 3\% for SM18R.

Evaluation of field spray schedules. In commercial fields, significant differences between sprayed and unsprayed plots occurred only in fields 2 and 5 (Table 2). In field 2, all fungicide treatments significantly reduced lettuce drop incidence. In field 5, only vinclozolin and dicloran significantly reduced lettuce drop incidence. Disease incidence was too low in fields 1 , 3 , and 4 to detect treatment differences.

\section{DISCUSSION}

No iprodione-resistant isolates of $S$. $m i$ nor were identified from lettuce fields in coastal California. However, consistent with previous reports $(5,7,9,13,17)$, resistance to iprodione developed readily in vitro. The dicarboximide fungicides are used mainly to control diseases caused by Botrytis, Sclerotinia, Monilinia (12), and Sclerotium spp. $(14,18)$. Most reports of resistance to dicarboximides involve $B o$ trytis spp., but the propensity of all these fungi, as well as several others, to form resistant strains is well documented $(5,7,9,13,17)$. Most, if not all, fungi tested produced resistant strains under laboratory conditions, but field isolations are also reported for many fungi (9), including $S$. minor (in a microplot planted with peanut and sprayed with iprodione) (3) and $S$. homoeocarpa (from a creeping bentgrass putting green sprayed with iprodione) (6).

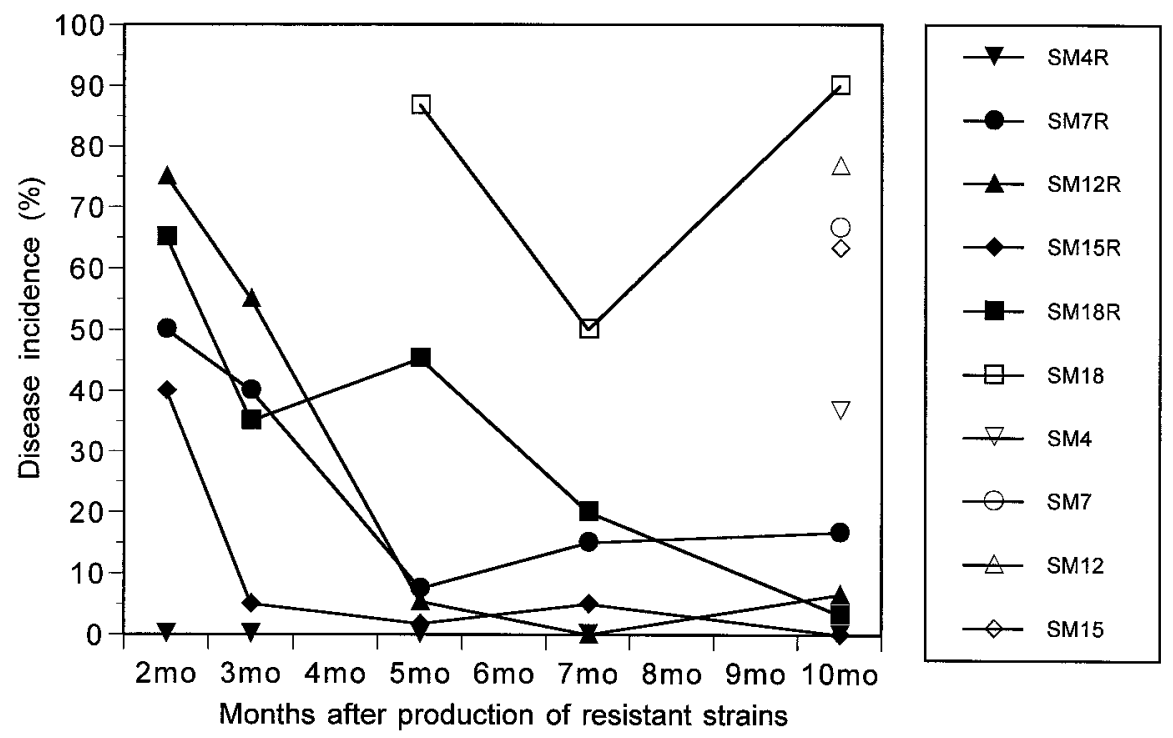

Fig. 4. Lettuce drop incidence caused by five wild-type Sclerotinia minor isolates (SM4 to SM18) and five iprodione-resistant strains (SM4R to SM18R). Resistant strains were tested for pathogenicity at 2 to 10 months after in vitro production and compared at 10 months with their wild-type counterparts. 
Previous studies of peanut isolates of $S$. minor $(4,13)$ reported frequencies of in vitro development of resistance to dicarboximides (either $2 \mu \mathrm{g}$ of iprodione and vinclozolin or 10 and $100 \mu \mathrm{g}$ of procymidone per $\mathrm{ml}$ ) of 1.8 and $2.3 \%$. A recent study (16) reported that $6 \%$ of $S$. minor field isolates tested grew at $2 \mu \mathrm{g}$ of iprodione per ml. Our isolates showed a much higher rate of production of resistant strains: after a 2-week incubation on iprodione-amended media, all 20 of the isolates tested here produced growth tolerant to the fungicide at $5 \mu \mathrm{g} / \mathrm{ml}$. Porter and Phipps (13) reported that about $50 \%$ of their procymidone-resistant peanut isolates retained fungicide resistance after transfer to procymidone-amended media. Ninety-seven percent of California lettuce isolates retained resistance in vitro on $5 \mu \mathrm{g} / \mathrm{ml}$ for at least 5 months. Our study showed that mature mycelium was able to initiate resistant growth more rapidly than was vegetative mycelium, and that some sclerotia from 19 out of 20 isolates tested were able to germinate within 5 weeks on 100 $\mu \mathrm{g}$ of iprodione per $\mathrm{ml}$.

Reports are varied on the ability of dicarboximide-resistant isolates, especially in vitro-derived isolates, to cause disease on dicarboximide-sprayed plants $(7,9,17)$. In vitro-derived (4) and in vivo (field)derived (16) fungicide-resistant strains of $S$. minor from peanut were virulent, but control by dicarboximides in the field was equal to that achieved against sensitive isolates, even after 6 years of iprodione use in microplots infested with insensitive isolates. In our field study, however, iprodione sprays that significantly reduced lettuce drop incited by wild-type isolates of $S$. minor failed to reduce lettuce drop caused by a virulent iprodione-resistant strain. There is evidence that dicarboximide-resistant fungi are less fit than their sensitive counterparts $(6,7,9,15)$; however, some researchers have reported highly fit and virulent isolates $(4,7,9)$. Our strains appeared to remain viable and to retain fungicide resistance, but virulence declined within months of their production.

Table 2. Lettuce drop incidence in different fungicide treatments in five fields in the Salinas Valley during 1993 and 1994

\begin{tabular}{|c|c|c|c|c|c|}
\hline \multirow[b]{2}{*}{ Treatments } & \multicolumn{5}{|c|}{ Lettuce drop at location $(\%)^{\mathrm{a}}$} \\
\hline & 1 & 2 & 3 & 4 & 5 \\
\hline Iprodione, post-thinning, $2.24 \mathrm{~kg} / \mathrm{ha}$ & 2.7 & 4.9 & 0.5 & 1.3 & 12.3 \\
\hline Vinclozolin, post-thinning, $2.24 \mathrm{~kg} / \mathrm{ha}$ & 2.1 & 4.3 & 0.3 & 1.4 & 7.7 \\
\hline Dicloran, post-thinning, $4.48 \mathrm{~kg} / \mathrm{ha}$ & 3.0 & 4.9 & 0.3 & 1.5 & 7.6 \\
\hline $\begin{array}{l}\text { Iprodione, postplanting, } 1.12 \mathrm{~kg} / \mathrm{ha} \\
\text { + post-thinning, } 2.24 \mathrm{~kg} / \mathrm{ha}\end{array}$ & 3.2 & 3.7 & 0.4 & $\ldots$ & $\ldots$ \\
\hline $\begin{array}{l}\text { Iprodione, postemergence, } 1.68 \mathrm{~kg} / \mathrm{ha} \\
\text { + post-thinning, } 1.68 \mathrm{~kg} / \mathrm{ha}\end{array}$ & 3.2 & 3.6 & 0.2 & $\ldots$ & ... \\
\hline $\begin{array}{l}\text { Dicloran }(4.48 \mathrm{~kg} / \mathrm{ha})+\text { iprodione }(2.24 \mathrm{~kg} / \mathrm{ha}) \text {, } \\
\text { post-thinning }\end{array}$ & $\ldots$ & $\ldots$ & 0.3 & $\ldots$ & $\ldots$ \\
\hline Untreated control & 3.1 & 10.2 & 0.4 & 3.3 & 14.2 \\
\hline $\operatorname{LSD}(P \leq 0.05)$ & $\ldots$ & 3.5 & $\ldots$ & $\ldots$ & 2.1 \\
\hline
\end{tabular}

${ }^{\mathrm{a}}$ Ratio of the number of plants exhibiting symptoms of lettuce drop immediately before harvest to the total plants evaluated, expressed as percentage.
In coastal California, lettuce crops mature about 8 weeks after fungicide application, and lettuce drop incidence often increases just before harvest. The high rate at which resistance arose in the laboratory within 5 weeks and its high rate of retention, combined with the ability of some sclerotia to germinate in the presence of the fungicide, suggest that there is a potential for fungicide resistance to occur in dicarboximide-sprayed lettuce fields and to overcome disease control by dicarboximide fungicides. However, loss of virulence over time in our isolates suggests that the threat posed in lettuce fields by resistance may be limited. In Virginia, resistance in peanut isolates has been persistent, even after several years without iprodione sprays, but there has been no evidence of loss of disease control by iprodione in commercial fields (16).

Our studies on the efficacy of the currently used fungicides and spray schedules yielded conclusive results from only two fields. Very low lettuce drop incidence in three out of five fields prevented detection of treatment differences. Also, in field 1, rains in late May (unusual in coastal California) delayed fungicide treatments, which then had to be applied to larger than optimal plants, counter to the intention of the study. In fields 2 and 5, the fungicides significantly reduced lettuce drop incidence compared with untreated controls.

It is likely that production schedules influence fungicide effectiveness in lettuce drop management. Lettuce seedlings at the thinning stage grow rapidly, and quickly produce large leaves. Factors such as weather and labor work schedules can delay thinning until several days later than planned, resulting in overly large leaves that block fungicide delivery to the plant crowns. In addition, a newly thinned lettuce field is sensitive to water stress. Growers will sometimes schedule an irrigation immediately after thinning is completed, making the ground too wet for spray equipment to pass and delaying the post-thinning fungicide application. Fungicide coverage is thus compromised due to production decisions that result in plants with large leaves.

There are several reports of loss of effectiveness of dicarboximide fungicides after continued use in commercial settings, and there is evidence that this loss of effectiveness is linked to a buildup of soil microorganisms that degrade the fungicides more rapidly than in fields with no history of dicarboximide use $(11,14,18)$. Martin et al. (11) reported that a loss of effectiveness of iprodione for control of lettuce drop incited by $S$. minor in France was strongly linked with a history of iprodione treatment, which was correlated with a high rate of microbial degradation of the fungicide. In this study, we found no evidence that lack of disease control in coastal California is due to the occurrence of iprodione-resistant strains; improper timing of spray schedules may be a factor. The possibility that poor disease control in coastal California is because of a buildup of soil microflora that rapidly degrade the fungicides should be investigated.

\section{ACKNOWLEDGMENTS}

We thank the Iceberg Lettuce Advisory Board and Rhone-Poulenc Ag Company for their support, and the following individuals for their assistance: Bruce Bates, Richard Del Piero, Ken Dunster, Hal Faulkner, Teo Gonzales, Walt Maitoza, Glenn McMillan, Matt Mulanax, Jeff Taylor, Larry Tokiwa, and Maria Vidauri.

\section{LITERATURE CITED}

1. Abawi, G. S., Robinson, R. W., Cobb, A. C., and Shail, J. W. 1980. Reaction of lettuce germ plasm to artificial inoculation with Sclerotinia minor under greenhouse conditions. Plant Dis. 64:668-671.

2. Adams, P. B., and Tate, C. J. 1976. Mycelial germination of sclerotia of Sclerotinia sclerotiorum on soil. Plant Dis. Rep. 60:515-518.

3. Brenneman, T. B., Phipps, P. M., and Stipes R. J. 1987. In vivo dicarboximide resistance in Sclerotinia minor from peanut. (Abstr.) Phytopathology 77:639.

4. Brenneman, T. B., Phipps, P. M., and Stipes, R. J. 1987. Sclerotinia blight of peanut: Relationship between in vitro resistance and field efficacy of dicarboximide fungicides. Phytopathology 77:1028-1032.

5. Brenneman, T. B., Phipps, P. M., and Stipes, R. J. 1987. Control of Sclerotinia blight of peanut: Sensitivity and resistance of Sclerotinia minor to vinclozolin, iprodione, dicloran, and PCNB. Plant Dis. 71:87-90.

6. Detweiler, A. R., Vargas, J. M., Jr., and Danneberger, T. K. 1983. Resistance of Sclerotinia homoeocarpa to iprodione and benomyl. Plant Dis. 67:627-630.

7. Gouot, J.-M. 1988. Characteristics and population dynamics of Botrytis cinerea and other pathogens resistant to dicarboximides. Pages 53-55 in: Fungicide Resistance in North America. C. J. Delp, ed. American Phytopathological Society, St. Paul, MN.

8. Hubbard, J. C., and Subbarao, K. V. 1994. Fungicide resistance in California isolates of Sclerotinia minor. (Abstr.) Phytopathology 84:1139.

9. Lorenz, G. 1988. Dicarboximide fungicides: History of resistance development and monitoring methods. Pages 45-51 in: Fungicide Resistance in North America. C. J. Delp, ed. American Phytopathological Society, St. Paul, $\mathrm{MN}$. 
10. Marcum, D. B., Grogan, R. G., and Greathead, A. S. 1977. Fungicide control of lettuce drop caused by Sclerotinia sclerotiorum 'minor'. Plant Dis. Rep. 61:555-559.

11. Martin, C., Davet, P., Vega, D., and Coste, C. 1991. Field effectiveness and biodegradation of cyclic imides in lettuce field soils. Pestic. Sci. 32:427-438.

12. Pommer, E. H., and Lorenz, G. 1987. Dicarboximide fungicides. Pages 91-106 in: Modern Selective Fungicides: Properties, Applications, Mechanisms of Action. H. Lyr, ed. Longman Scientific \& Technical, Harlow, Essex, England.
13. Porter, D. M., and Phipps, P. M. 1985. Effects of three fungicides on mycelial growth, sclerotium production, and development of fungicide-tolerant isolates of Sclerotinia minor. Plant Dis. 69:143-146.

14. Slade, E. A., and Fullerton, R. A. 1992. Degradation of dicarboximide fungicides iprodione, vinclozolin, and procymidone in Patumahoe clay loam soil, New Zealand. Pestic. Sci. 35:95-100.

15. Smith, F. D., Phipps, P. M., and Stipes, R. J. 1991. Agar plate, soil plate, and field evaluation of fluazinam and other fungicides for control of Sclerotinia minor on peanut. Plant
Dis. 75:1138-1143.

16. Smith, F. D., Phipps, P. M., Stipes, R. J., and Brenneman, T. B. 1995. Significance of in sensitivity of Sclerotinia minor to iprodione in control of Sclerotinia blight of peanut. Plant Dis. 79:517-523.

17. Staub, T. 1991. Fungicide resistance: Practical experience with antiresistance strategies and the role of integrated use. Annu. Rev. Phytopathol. 29:421-442.

18. Walker, A., and Welch, S. J. 1990. Enhanced biodegradation of dicarboximide fungicides in soil. Pages 53-67 in: A.C.S. Symp. Ser. Am. Chem. Soc. Washington, DC. 